\title{
OPTIMALISASI CAPAIAN PEMBELAJARAN MATAKULIAH BERBASIS PEMROGRAMAN MELALUI MEDIA E-LEARNING
}

\author{
Ratna Dewi $^{1}$, Silfia Rifka ${ }^{2}$, Rikki Vitria ${ }^{3}$, Uzma Septima $^{4}$, Ramiati $^{5}$ \\ 1,2,3,4,5 Program Studi Teknik Telekomunikasi, Jurusan Teknik Elektro, Politeknik Negeri Padang \\ Kampus Politeknik Negeri Padang, Limau Manis, Padang, 25163 \\ Email: ratnadewi@pnp.ac.id, silfia_rifka@ pnp.ac.id.ac.id, rikkivitria@ pnp.ac.id.ac.id, \\ uzmaseptima@gmail.com,ramiati76@gmail.com
}

\begin{abstract}
ABSTRAK
Pandemik Covid-19 yang dialami seluruh dunia saat ini termasuk Indonesia, memaksa pembelajaran dilakukan secara daring atau e-learning termasuk pada Politeknik Negeri Padang. Dengan kendala yang ada pada mahasiswa sebagai peserta didik dalam sistem pembelajaran ini yaitu kendala dalam mengakses sistem melalui jaringan internet dan belum semua mahasiswa memiliki perangkat komputer yang dibutuhkan dalam mengaplikasikan matakuliah berbasis pemrograman. Agar capaian pembelajaran tetap bisa dicapai secara optimal maka dalam penelitian ini dibuat web untuk sistem pembelajaran daring atau e-learning. Dari hasil penggunaan web ini 82,9\% mahasiswa memahami materi yang ditayangkan dalam web tersebut dan sebagain besar mahasiswa menginginkan materi dalam bentuk video offline sehingga dapat digunakan setiap saat.
\end{abstract}

Kata Kunci: pembelajaran daring, e-learning, web

\section{ABSTRACT}

The Covid-19 pandemic currently experienced throughout the world, including Indonesia, forces learning to be carried out online or e-learning, including at the Politeknik Negeri Padang. With the obstacles that exist for students as learners in this learning system, namely constraints in accessing the system through the internet network and not all students have the computer equipment needed to apply programming-based courses. So that learning outcomes can still be achieved optimally, in this study a web is made for online learning systems or e-learning. From the results of using this web, $82.9 \%$ of students understand the material displayed on the web and most students want the material in the form of offline video so that it can be used at any time.

Keywords: online learning, e-learning, web

\section{Pendahuluan}

Pembelajaran daring sudah dilakukan sejak lama, namun pada saat pandemik COVID-19 ini mengharuskan sistem pembelajaran secara daring atau jarak jauh. Dengan kondisi seperti ini, maka mengharuskan pengajar untuk membuat suatu metode pembelajaran daring agar berjalan efektif dan capaian pembelajaran bisa dicapai dengan optimal.

Pada [1] yang meneliti tentang Online Interactive Learning Model (OILM) menggunakan media sosial telah mampu meningkatkan pemahaman materi mahasiswa hingga lebih dari $81 \%$ dibanding dengan tatap muka. Menurut [2] yang telah meneliti dengan mengembangkan metode pembelajaran daring dengan fokus pada blended learning dengan model Integrative Learning Design Framework (ILDF) yang mendapatkan hasil bahwa sebagian besar responder memiliki gaya belajar visual dan menggunakan internet untuk mengakses informasi. Menurut penelitian [3], dinyatakn bahwa salah satu cara menyampaikan informasi pembelajaran adalah melalui web blog dan hal ini akan meningkatkan kemampuan baca mahasiswa.

Sementara itu pada [4], meneliti mengenai bagaiman efek dari rancangan pembelajaran, penilaian, karakteristik instruktur pada penggunaan sistem e-learning. bertujuan untuk menyelidiki faktor penentu utama yang dapat memainkan peran penting meningkatkan penggunaan dan penerimaan sistem e-learning di kalangan siswa Model penelitian diuji dengan teknik structural equation modeling (SEM). Berdasarkan hasil, faktor desain kursus, dukungan konten kursus, penilaian kursus dan karakteristik instruktur terbukti memiliki pengaruh yang signifikan pada penggunaan sistem e-learning yang sebenarnya. Dan pada [5] menyatakan bahwa dengan pandemik Covid-19 ini melalui pembelajaran daring akan membuat siswa menjadi mandiri dan siswa dapat mengakses informasi melalui smartphone yang mereka miliki. Pada [6] dilakukan penellitian tentang bagaimana pengaruh pembelajaran daring terhadap mahasiswa ditengah 
Covid-19, disini dinyatakan bahwa pembelajaran daring ini dilakukan sebagai salah satu cara untuk memutus mata rantai penyebaran Covid dengan pembelajaran virtual disamping itu mahasiswa dapat belajar secara mandiri.

Saat ini semua universitas menerapkan elearning, bahkan hal mengharuskan mereka untuk menemukan model yang tepat dalam pembelajaran agar tetap terjaga kualitas dalam pelaksanaannya seperti yang dikemukan pada [7]. Dalam penelitian tersebut mengusulkan mengenai bagaimana proses yang berorientasi pada kualitas untuk model global dengan menerapkan standar pelaksanaan yang baik dengan sepearangkat standar dan praktiknya dari semua benua dengan menggunakan metode kuantitatif dan kualitatif.

Kondisi yang sama dengan penelitian sebelumnya, bahwa Politeknik Negeri Padang juga menerapkan sistem pelajaran daring selama pandemik Covid-19, dan harus menemukan metode yang tepat untuk pembelajaran ini. Dalam penelitian ini, peneliti membuat suatu web pembelajaran e-learning dengan studi kasus pada matakuliah pemrograman pada Program Studi Teknik Telekomunikasi dan menerapkan pada mahasiswa. Setelah web ini diterapkan, dilakukan evalusasi melalui kuesioner kepuasan mahasiswa terhadap web tersebut dari segi materi kulaih yang dipaparkan pada web, apakah sistem e-learning pada web ini, membantu mahasiswa dalam penyerapan atau pemahaman terhadap materi yang diberikan. Tercapainya capaian pembelajaran adalah hal yang paling penting dalam sistem pembelajaran di perguruan Tinggi dan hal ini akan terlihat dari kompetensi yang dimiliki oleh mahasiswa. Dengan pembuatan web khusus untuk matakuliah pemrograman di Program Studi Teknik Telekomunikasi (PSTT) Politeknik Negeri Padang (PNP), diharapkan akan membantu optimalisasi pencapainnya.

\section{Metode Penelitian}

E-learning adalah suatu sistem pendidikan berbasis komputer yang memungkinkan peserta didik dapat belajar dimana saja dan kapan saja, yang dalam perkembangannya hingga saat ini sistem ini sudah diakses melalui internet. permasalah geografis dapat diatasi dengan metode e-learning karena akan dijembatani oleh perkembangan teknologi yang membuat seolaholah seseorang berada dalam sebuah kelas. Dalam e-learning seseorang bisa berbagi materi dalam berbagai format seperti file dokumen, video, gambar dan lain-lain hingga bisa melakukan webinar [8]. Dengan mempertimbangkan beberapa hal tersebut maka Tahapan yang dilakukan dalam metode penelitian ini dapat dilihat pada Gambar 1.
Pada kegiatan ini dilakukan literasi yang berkaitan dengan penelitian meliputi pembuatan web dan survey kebutuhan informasi yang akan ditampilkan pada web, pendukung lainnya.

\section{Perancangan Web}

Pada penelitian ini, web dibuat dengan memberikan beberapa informasi dalam perkuliahan. Dengan harapan informasi tersebut membantu mahasiswa untuk memahami materi yang disampaikan sehingga dalam kondisi jauhpun mahasiswa dapat mengikuti perkuliahan. Tabel 1 menampilkan kebutuhan. dalam rancangan web untuk pembelajaran ini.

\section{Pembuatan Web}

Web dibuat berdasarkan komponen rancangan, menggunakan bahasa php-mysql. Kemudian web di hosting sehingga dapat diakses oleh mahasiswa sebagai sasaran utama pengguna web.

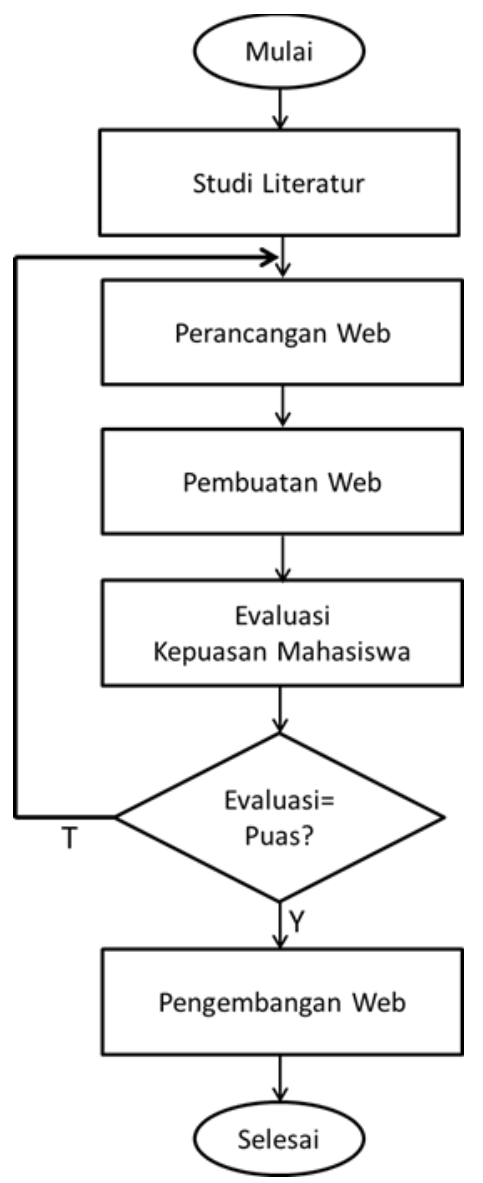

Gambar 1. Flowchart metode penelitian 
Tabel 1. Komponen rancangan web

\begin{tabular}{ll}
\hline Komponen & \multicolumn{2}{c}{ Keterangan } \\
\hline Home & $\begin{array}{l}\text { Halaman ini terbuka saat pertama } \\
\text { mengunjungi alamat } \\
\text { https://spadapstt.com. Berisi tentang }\end{array}$ \\
& $\begin{array}{l}\text { informasi matakuliah berbasis } \\
\text { pemrograman. }\end{array}$ \\
Login & $\begin{array}{l}\text { Halaman ini digunakan untuk } \\
\text { mengakses matakuliah. Dibagi }\end{array}$ \\
& menjadi 3 bagian yaitu admin, \\
& $\begin{array}{l}\text { teacher dan participant } \\
\text { (mahasiswa) baik yang sudah punya }\end{array}$ \\
& $\begin{array}{l}\text { akun atau dapat mendaftar sendiri } \\
\text { pada halaman ini. }\end{array}$ \\
Dashboard & $\begin{array}{l}\text { Halaman ini berisi semua informasi } \\
\text { utama dari web. }\end{array}$ \\
Courses & $\begin{array}{l}\text { Halaman ini berisi uraian detail } \\
\text { tentang matakuliah }\end{array}$ \\
Hak Akses & $\begin{array}{l}\text { Dibagi dalam } 3 \text { kategori yaitu admin } \\
\text { dapat melakukan pengaturan apapun }\end{array}$ \\
terhadap web (punya hak penuh). \\
Teacher dapat melakukan \\
pengaturan pada matakuliah seperti \\
input materi, pemberian tugas, \\
absensi dan mengatur ujian. \\
Participant hanya dapat mengikuti \\
perkuliahan.
\end{tabular}

\section{Evaluasi Kepuasan Mahasiswa}

Dalam hal ini mahasiswa diberikan beberapa pertanyaan melalui form aplikasi, yang merupakan kuesioner untuk menjajaki apakah dengan adanya web ini akan membantu mahasiswa dalam memahami materi selama perkuliahan daring atau e-learning ini, khususnya selama pandemik Covid-19. Jika hasil memberikan dampak yang positif maka akan web akan dikembangkan pada tahap berikutnya, jika belum memberikan dampak yang baik, maka web akan direvisi ulang dengan menyajikan informasi lebih efektif sehingga pemahaman mahasiswa terhadap materi lebih ditingkatkan dan seolah-olah mereka sedang melakukan tatap muka dalam kelas.

\section{Pengembangan Web}

Web akan terus dikembangakan kedepannya walaupun pandemik ini sudah berlalu. Karena web ini dibuat sebagai salah satu media untuk belajar mandiri mahasiswa sehingga mahasiswa dapat mengembangkan kemampuan diri dengan tidak bergantung kepada pertemuan tatap muka langsung dengan tim pengajar.

\section{Hasil dan Pembahasan}

Pembuatan web pada penelitian ini, disesuaikan dengan komponen yang terdapat pada Tabel 1.

\section{Halaman Home}

Pada halaman ini, ditampilkan semua informasi tentang matakuliah seperti materi matakuliah, jumlah sks, jam serta pengajar (teacher). Tampilan halaman ini dapat dilihat pada Gambar 2.

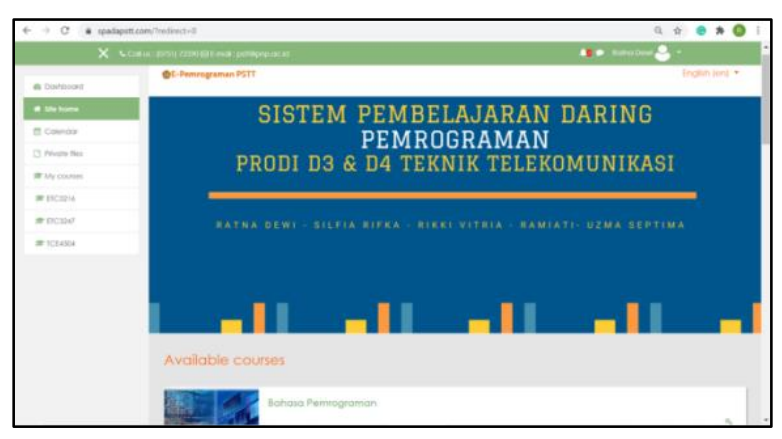

Gambar 2. Tampilan halaman home pada web

\section{Halaman Login}

Halaman ini digunakan untuk mengakses web, bagi admin, teacher dan participant baik yang sudah terdaftar atau registrasi baru bagi participant. Tampilan halaman Login ini dapat dilihat pada Gambar 3.

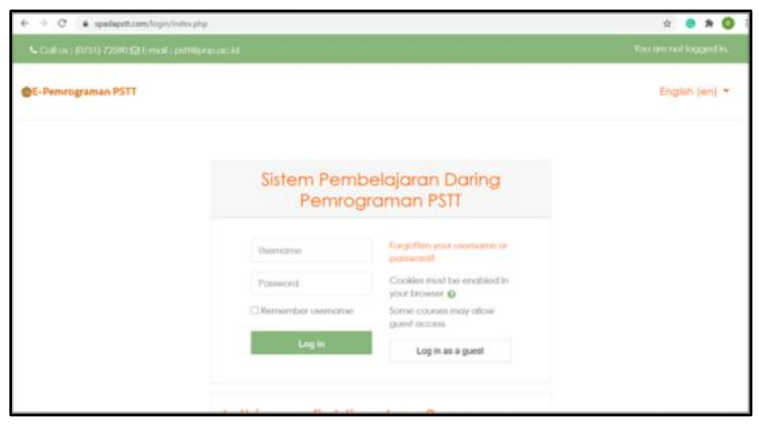

Gambar 3. Tampilan halaman login

\section{Halaman Dashboard}

Halaman ini berisi semua informasi utama web dan fitur-fitur yang dapat lihat pada web e-learning ini. Tampilan halaman ini dapat dilihat pada Gambar 4.

\section{Halaman Courses}

Pada halaman ini berisi informasi detail dari matakuliah yang meliputi materi kuliah setiap pertemuan, tugas, kuis, forum diskusi, daftar hadir dan lain-lain yang berhubungan dengan proses belajar mengajar. Tampilan halaman ini dapat dilihat pada Gambar 5 dan Gambar 6. 


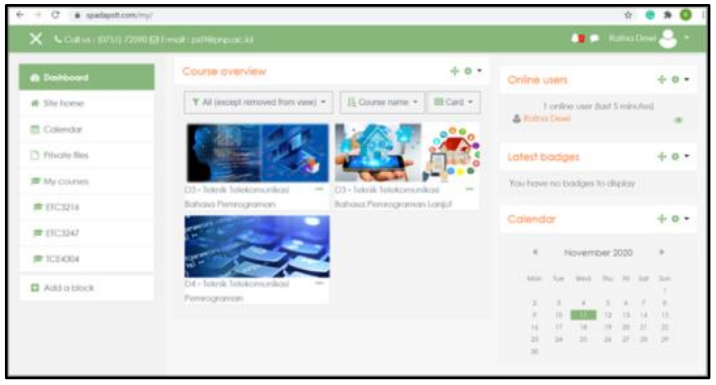

Gambar 4. Tampilan halaman dashboard

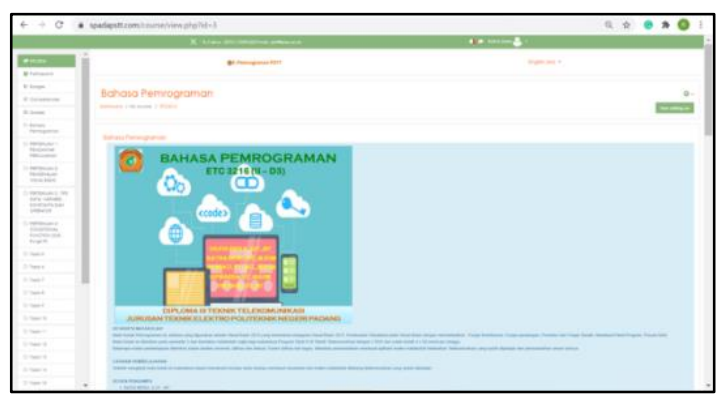

Gambar 5. Tampilan halaman courses

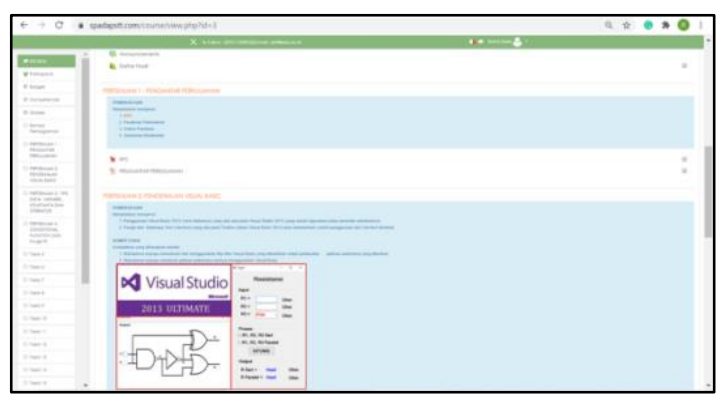

Gambar 6. Tampilan uraian materi kuliah

\section{Hasil Kuesioner Kepuasan Mahasiswa}

Pada penelitian ini, pemanfaatan web elearning ini bagi mahasiswa ditelusuri dengan memberikan kuesioner, apakah mahasiswa dapat memahami materi yang diberikan pada web. Berdasarkan kuesioner dipatkan hasil seperti Tabel 2. Pengisi kuesioner ini berjumlah 158 responden yang merupakan mahasiswa yang mengikuti perkuliahan daring matakuliah berbasis pemrograman pada Semester Ganjil Tahun Ajaran 2020/2021.

Dari Tabel 2 dapat dilihat bahwa belum seluruh mahasiswa memiliki perangkat komputer yang memadai sehingga ini menjadi kendala dalam mengaplikasikan materi dari matakuliah berbasis pemrograman di PSTT dan masih ada mahasiswa yang mengalami kendala dalam mengakses internet $(20,9 \%)$ salah satu penyebabnya adalah gangguan sinyal pada operator seluler yang digunakan oleh mahasiswa sehingga penggunaan teknologi informasi belum $100 \%$ efektif.
Tabel 2. Hasil kuesioner kepuasan mahasiswa

\begin{tabular}{|c|c|c|}
\hline Pertanyaan & $\begin{array}{l}\text { Persentase } \\
\text { responder }\end{array}$ & Keterangan \\
\hline \multicolumn{3}{|l|}{$\begin{array}{l}\text { Kesiapan } \\
\text { infrastruktur }\end{array}$} \\
\hline $\begin{array}{l}\text { Mahasiswa memiliki } \\
\text { perangkat komputer } \\
\text { yang memadai }\end{array}$ & $64.6 \%$ & Memiliki \\
\hline $\begin{array}{lr}\text { Memiliki } & \text { kendala } \\
\text { dalam } & \text { mengakses }\end{array}$ & $79.1 \%$ & $\begin{array}{l}\text { Tidak ada } \\
\text { kendala }\end{array}$ \\
\hline internet & $56.3 \%$ & Ya \\
\hline $\begin{array}{l}\text { Teknologi informasi } \\
\text { membuat }\end{array}$ & & \\
\hline $\begin{array}{l}\text { pembelajaran lebih } \\
\text { efektif }\end{array}$ & & \\
\hline \multicolumn{3}{|l|}{$\begin{array}{l}\text { Kualitas interaksi } \\
\text { akademik secara } \\
\text { daring }\end{array}$} \\
\hline Media pembelajaran & $46,2 \%$ & \\
\hline yang paling efektif: & $34.2 \%$ & \\
\hline Video offline & $13,9 \%$ & \\
\hline Video & $5.7 \%$ & \\
\hline Conference & $78,5 \%$ & Tertarik \\
\hline \multicolumn{3}{|l|}{ File Dokumen } \\
\hline \multicolumn{3}{|l|}{ Lain-lain } \\
\hline \multicolumn{3}{|l|}{$\begin{array}{l}\text { Ketertarikan dalam } \\
\text { mengikuti }\end{array}$} \\
\hline pembelajaran melalui & & \\
\hline $\begin{array}{l}\text { sistem pembelajaran } \\
\text { daring dan } e \text {-learning }\end{array}$ & $76,6 \%$ & Tercapai \\
\hline \multicolumn{2}{|l|}{ Pemahaman materi } & Berkualitas \\
\hline \multicolumn{3}{|l|}{ Pencapaian Learning } \\
\hline Outcomes & $80.4 \%$ & Setuju \\
\hline $\begin{array}{l}\text { Kualitas Bahan Ajar } \\
\text { pada web }\end{array}$ & $82.9 \%$ & Paham \\
\hline $\begin{array}{l}\text { Web mempermudah } \\
\text { belajar }\end{array}$ & & \\
\hline $\begin{array}{l}\text { Tingkat pemahaman } \\
\text { materi pada web }\end{array}$ & & \\
\hline
\end{tabular}

Media pembelajaran yang paling diminati mahasiswa adalah dalam bentuk video offline sehingga materi dapat diulang setiap saat. Tingkat pencapaian learning outcomes mahasiswa adalah $76,6 \%$ dan belum tercapainya secara penuh $(100 \%)$ karena masih ada kendala dalam sistem pembelajaran e-learning ini, namun dengan adanya web ini $80,4 \%$ mempermudah mahasiswa dalam belajar dengan capaian jumlah mahasiswa yang paham adalah $82,9 \%$.

Matakuliah berbasis pemrograman memang mengharuskan semua mahasiswa untuk mencobakan program secara langsung melalui perangkat komputer atau laptop namun karena belum semua mahasiswa memiliki perangkat tersebut, sehingga ini menjadi kendala utama dalam pembelajaran daring atau e-learning yang digunakan khususnya saat pandemik Covid-19 ini. 


\section{Kesimpulan}

Pada dasarnya penggunaan web ini dalam pembelajaran daring atau e-learning ini, akan sangat membantu mahasiswa dalam materi kuliah dengan hasil 82,9 \% walaupun sisanya masih terkendala dengan infrastruktur pembelajaran. Namun mahasiswa masih bisa mengikuti dengan memberikan materi lebih banyak dalam bentuk video offline sehingga dapat mengulang setiap saat melalui video tersebut. Dengan adanya tanggapan dari responder kuesioner ini, akan membantu peneliti dalam mengevalusi penggunaan web dan dapat menyempurnakan web sehingga benar-benar efektif digunakan dalam pembelajaran dan capaian pembelajaran bisa didapatkan secara optimal mendekati $100 \%$.

\section{Ucapan Terima Kasih}

Terima kasih kepada Politeknik Negeri Padang yang telah mendanai penelitian ini melalui Dana DIPA Politeknik Negeri Padang Tahun 2020

\section{Daftar Pustaka}

E. Kuntarto, "Keefektifan Model Pembelajaran Daring Dalam Perkuliahan Bahasa Indonesia di Perguruan tinggi," J. Indones. Lang. Educ. Lit., vol. 3, no. 1, pp. 53-65, 2017.

[2] R. Ramadhan, U. A. Chaeruman, and C. Kustandi, "Jurnal Pembelajaran Inovatif Pengembangan Pembelajaran Bauran ( Blended Learning ) di Universitas Negeri Jakarta," J. Pembelajaran Inov., vol. 1, no. 1, pp. 37-48, 2018.

[3] N. L. Khusniyah and L. Hakim, "Efektivitas Pembelajaran Berbasis Daring: Sebuah Bukti Pada Pembelajaran Bahasa Inggris," J. Tatsqif, vol. 17, no. 1, pp. 19-33, 2019.

[4] M. A. Almaiah and I. Y. Alyoussef, "Analysis of the Effect of Course Design, Course Content Support, Course Assessment and Instructor Characteristics on the Actual Use of E-Learning System," IEEE Access, vol. 7, pp. 171907-171922, 2019.

[5] O. I. Handarini and S. S. Wulandari, "Pembelajaran Daring Sebagai Upaya Study From Home (SFH) Selama Pandemi Covid 19," J. Pendidik. Adm. Perkantoran, vol. 8, no. 3, pp. 496-503, 2020.

[6] A. Sadikin and H. Afreni, "Pembelajaran Daring di Tengah Wabah Covid-19,"
BIODIK J. Ilm. Pendidik. Biol., vol. 06, no. 02, pp. 212-224, 2020.

[7] J. P. Vagarinho and M. Llamas-Nistal, "Process-Oriented Quality in e-Learning: A Proposal for a Global Model," IEEE Access, vol. 8, pp. 13710-13734, 2020.

[8] e-learning Concepts, Trends, Applications. San Francisco: Epignosis LLC, 2014. 